\title{
As transferências voluntárias do governo federal para a gestão de resíduos sólidos urbanos: um estudo da Região Metropolitana de São Paulo
}

\author{
The federal government's voluntary transfers to municipal solid \\ waste management: a study of the Metropolitan Region of São Paulo
}

Flávio Bordino Klein [I]

Sylmara Lopes F. Gonçalves-Dias [II]

Cecília Olivieri [III]

\begin{abstract}
Resumo
O objetivo deste trabalho é analisar as transferências voluntárias do governo federal para programas e ações na gestão de resíduos sólidos urbanos (RSU), incluindo os resultados nos municípios da Região Metropolitana de São Paulo (RMSP). A estratégia metodológica foi a pesquisa exploratória, de natureza qualitativa. Os dados secundários foram obtidos com base em documentos e fontes oficiais, especialmente dos Planos Plurianuais (PPAs), Portal da Transparência e Portal de Convênios. Constatou-se que a concentração desses repasses foi justamente para os municípios com alto e médio PIB per capita. Além disso, observou-se baixa eficácia no uso dos recursos federais, podendo ser atribuído ao limitado controle das transferências voluntárias e de coordenação da informação pelos órgãos executores.
\end{abstract}

Palavras-chave: transferências voluntárias; coordenação intergovernamental; resíduos sólidos urbanos (RSU); coleta seletiva; resultados das políticas públicas.

\begin{abstract}
The aim of this study is to analyze the federal government's voluntary transfers to programs and actions related to municipal solid waste management (MSWM), providing results of municipalities in the metropolitan region of São Paulo. The methodological strategy was the qualitative exploratory research. Secondary data were obtained from documents and official sources, especially from the Pluriannual Plans, the Transparency Portal and the Agreements Portal. It was found that the concentration of such transfers was precisely on municipalities with high and medium GDP per capita. Moreover, low efficacy was observed in the use of federal resources, which can be attributed to a limited control of the voluntary transfers and of information coordination by the implementing bodies.
\end{abstract}

Keywords: voluntary transfers; intergovernmental coordination; municipal solid waste (MSW); curbside recycling; results of public policies. 


\section{Introdução}

Este artigo apresenta os resultados do estudo sobre as transferências voluntárias do governo federal para programas e ações na Gestão Integrada de Resíduos Sólidos Urbanos (Girsu). Esse tipo de transferência fiscal caracteriza-se, essencialmente, por não ter critérios constitucionais ou legais de partilha (Arretche e Rodden, 2004). Pelo viés discricionário sobre a seleção do beneficiário, a pesquisa procurou analisar se essas transferências priorizaram municípios de menor poder econômico e se geraram resultados na gestão de Resíduos Sólidos Urbanos (RSU) nos entes beneficiados. 0 tema é relevante devido não apenas à baixa cobertura dos serviços de saneamento e aos decorrentes problemas nas áreas de saúde e meio ambiente, mas também devido aos aspectos institucionais envolvidos. Nesse contexto, destacam-se, especialmente, as mudanças no planejamento e investimento em saneamento no País e as transformações das relações federativas no pós-Constituição de 1988.

Dispostos de maneira irregular nos lixões, ruas, rios, córregos e terrenos vazios, os resíduos sólidos têm o potencial de causar impactos ambientais negativos, como assoreamento de rios e córregos, degradação do solo e proliferação de vetores de importância sanitária (Brasil, 2010a; Silva e Liporone, 2011). Ao mesmo tempo, as condições inadequadas de habitação e infraestrutura urbana afetam diretamente a saúde humana. $\mathrm{A}$ aglomeração da população mais pobre e marginalizada em loteamentos irregulares e locais insalubres como margens de córregos, áreas com alta declividade ou próximas de descarte irregular de lixo - amplia a sua vulnerabilidade (Pasternak e Bógus, 2011).
No caso propriamente dos resíduos sólidos, há ainda no País o predomínio de sua destinação diretamente para aterros: "paga-se para 'enterrar' resíduos que, muitas vezes, poderiam ser primeiramente reduzidos, ou então reciclados" (Santos e Gonçalves-Dias, 2012, p. 150). Além da necessidade de eliminar as formas inadequadas de disposição em solo (lixões e aterros controlados), o País ainda precisa ampliar os investimentos para universalizar a coleta seletiva de resíduos e utilizar tecnologias adequadas para reaproveitamento e reciclagem (Zanta, 2009), adequando-se às diretrizes da Política Nacional de Resíduos Sólidos (PNRS), lei federal aprovada após 21 anos de tramitação no Congresso Nacional entre 1989-2010 (Araújo, 2012).

No contexto atual na gestão de resíduos sólidos, os municípios brasileiros deparam-se com duas realidades paralelas: 1) pela via "moderna", empreiteiras do setor de engenharia conseguem coletar grandes quantidades de resíduos sólidos e, por meio dos aterros sanitários, eles são aparentemente solucionados (enterrados com o mais avançado estado da arte); ou 2) a utilização "arcaica" pelo simples descarte em lixões. Ambas se baseiam no mesmo paradigma do NIMBY (not in my backyard não no meu quintal), o qual pressupõe afastar ao máximo os problemas ambientais ocasionados pelos resíduos sólidos, externalizando-os para municípios e localidades periféricas (Altvater, 1995 e Klein, 2017).

A PNRS apresenta dois principais desafios para o País, embora não sejam os únicos. O primeiro é eliminar a disposição final inadequada pelo uso dos lixões. Essa situação é muito mais crítica nas regiões Nordeste e Norte, as quais apresentam as maiores proporções de municípios que destinam os resíduos em 
lixões, além do grande desperdício de recursos públicos destinados para aterrá-los quando poderiam ser reduzidos ou reciclados (Santos e Gonçalves-Dias, 2012).

Dados do antigo Ministério das Cidades (MCidades), por meio do Sistema Nacional de Informações sobre Saneamento (SNIS), revelam que, em 2015, o País tinha uma estimativa de déficit de 17,64 milhões de brasileiros sem acesso à coleta regular de resíduos domiciliares, o que representava 8,6\% dos 204 milhões de habitantes naquele ano (Brasil, 2017). Quanto às formas de disposição final em solo, no mesmo ano, dos 3475 municípios que informaram ao SNIS a destinação final de seus RSU, 1.123 destinavam em lixões (32,3\%), 704 destinavam em aterros controlados (20,3\%) e 1.648 destinavam em aterros sanitários $(47,4 \%)$ (ibid.).

O segundo desafio da PNRS é a redução, reaproveitamento e reciclagem de resíduos sólidos, incluindo a adoção da coleta seletiva, ações essenciais para se atingir a meta de enviar somente os rejeitos para os aterros (Santos e Gonçalves-Dias, 2012).

Aqui cabe diferenciar os termos resíduos e rejeitos. A partir do que sobra de determinado produto (embalagem, casca, por exemplo) ou processo após o uso do produto, gera-se o resíduo sólido, que pode ser consertado, servir para outra finalidade (reuso) ou, ainda, ser reciclado. Já o rejeito é um tipo específico de resíduo sólido: "quando todas as possibilidades de reaproveitamento ou reciclagem já tiverem sido esgotadas e não houver solução final para o item ou parte dele, trata-se de um rejeito, e a única destinação plausível é encaminhá-lo para um aterro sanitário licenciado ambientalmente" (Brasil, 2010b).
Nesse processo, um dos benefícios ambientais diretos da implantação da coleta seletiva e reciclagem, no nível municipal, seria a redução dos materiais recicláveis encaminhados aos aterros. Haveria, ainda, benefícios econômicos e sociais relacionados com geração de empregos e renda para os catadores de materiais recicláveis, sendo a coleta seletiva, nesse caso, relevante para gerar melhores condições de trabalho para esse grupo social (Cherfem, 2015).

Apesar da relevância da PNRS, seu cumprimento efetivo não é trivial, tampouco garantido, devido às características da descentralização no País: grande heterogeneidade entre os entes federativos, parca tradição de provisão de serviços no plano local, baixa profissionalização da burocracia pública, pouca efetividade do controle público em estados e municípios (Abrucio, 2002; Rezende, 1995; Veloso et al., 2011).

A institucionalização das políticas ambientais, em países como o Brasil, ainda não apresentou uma implementação efetiva nas cidades. Há, ainda, uma distância considerável entre o discurso formal contido nas agendas e documentos e a realidade socioambiental dessas cidades. Torna-se necessária a construção de políticas públicas integradas que atuem nas diversas causas dos problemas socioambientais urbanos (Silva e Travassos, 2008).

A Constituição Federal de 1988 introduziu alterações no sistema federalista brasileiro, inaugurando um processo de descentralização, com a transferência de recursos e encargos da União para governos estaduais e municipais. Ao ampliar as competências políticas e administrativas dos municípios, a nova Constituição aumentou a transferência de 
recursos fiscais para os governos locais (Farah, 2006), sendo denominadas transferências obrigatórias. Todavia, há também a possibilidade de a União transferir recursos aos municípios de forma discricionária ou voluntária, seja para atender a critérios redistributivos (redução da desigualdade), seja para implementar políticas setoriais, incentivando os municípios a aderirem às políticas formuladas no nível federal (Miranda Soares e Guimarães de Melo, 2016; Prado, Quadros e Cavalcanti, 2003). Nesse contexto, os aportes federais através das transferências voluntárias tornam-se relevante para os municípios implementarem políticas públicas em saneamento básico, incluindo a gestão de RSU.

Esses recursos fiscais podem criar um elo entre os diferentes níveis de governo, subsidiando e auxiliando os municípios que tenham baixos recursos financeiros, tecnológicos e institucionais a internalizar os custos sociais e ambientais. Entretanto, existe a necessidade de critérios adequados que garantam o controle, monitoramento e avaliação sobre o uso desses recursos pelos municípios beneficiados e que se coadunem em eficiência e resultados - efeitos ou impactos - relacionados ao atendimento dos objetivos das políticas públicas (Olivieri, 2010; Pollitt e Bouckaert, 2011; Silva e Costa, 1995). Para fins deste estudo, optou-se pela análise dos resultados e não dos impactos das transferências voluntárias do governo federal para a gestão de resíduos sólidos urbanos. Impacto refere-se a nexo causal entre resultados do programa/ projeto e condições sociais da população, e resultado refere-se aos objetivos do programa (conforme Ramos e Schabbach, 2012), e é disto que 0 artigo trata.
Ao analisarmos indicadores que mensuram variáveis de manejo de RSU dos municípios estudados (existência do serviço de coleta seletiva, aumento da taxa de reciclagem, aumento do número de galpões de triagem, existência de lixões e inclusão dos catadores na Girsu), concluímos que os resultados gerados, em comparação com o volume de recursos federais recebidos para programas e ações na gestão dos RSU, foram bastante modestos nos municípios da RMSP beneficiados pelos repasses, considerando os objetivos propostos pelos Planos Plurianuais (PPA). Além disso, a maior parte desses recursos foi direcionada para os municípios de médio e elevado nível econômico, o que indica divergências em relação aos princípios e diretrizes relativos à redução da desigualdade regional e federativa.

Este artigo está estruturado em mais quatro seções, além desta introdução. $\mathrm{Na}$ seção 2, a revisão da literatura apresenta a descentralização de políticas públicas e dos mecanismos de apoio adotados pelo governo federal, como as transferências voluntárias de recursos fiscais, para a implementação de políticas públicas. Na seção 3, os procedimentos metodológicos explicitam os critérios para coleta de dados, a periodicidade e a escolha da unidade de análise. Na seção 4, são apresentados os valores dos repasses da União e quais municípios da RMSP foram beneficiados; e, posteriormente, analisaram-se indicadores dos programas de coleta seletiva e reciclagem de resíduos sólidos. As considerações finais apontam alguns resultados que podem ser atribuídos a essas transferências, bem como inconsistências e limites na obtenção e coordenação das informações, pelo governo federal, sobre as transferências desses recursos. 


\section{Descentralização de políticas públicas e as transferências fiscais no federalismo brasileiro}

O processo de descentralização promovido desde o começo dos anos 1990 pelo governo federal levou a um vertiginoso aumento de ações federais executadas pelos estados e municípios. Áreas como saúde, assistência social, segurança alimentar, educação básica, esporte e cultura, apoio à agricultura familiar e reforma agrária, saneamento e habitação são executadas, em boa parte, no âmbito subnacional mediante transferências de recursos do orçamento da União (Garcia, 2015). Em virtude dessa descentralização à sombra da desigualdade federativa, muitas políticas terão de ser necessariamente financiadas (pelo menos em parte) por recursos federais como forma de garantir a sua efetividade, sendo essencial a coordenação intergovernamental e interorganizacional para induzir e apoiar a implementação de diversos programas (Abrucio, 2002; O'Toole, 2003). Tais transferências devem também priorizar municípios e regiões com menor capacidade econômica e institucional, reduzindo as desigualdades do nosso federalismo:

As desigualdades demográficas e territoriais entre estados não são alheias às crescentes disparidades na qualidade de serviços essenciais prestados às populações. Os pequenos estados não alcançam a densidade mínima de recursos requerida para prestar adequadamente muitos desses serviços. E muito menos para exercer uma ação promocional efetiva no campo do desenvolvimento econômico. (Furtado, 1999, pp. 54-55)
As informações do Produto Interno Bruto (PIB) permitem comparar, entre outros aspectos, a concentração econômica e a renda per capita entre países (Altvater, 1995). No caso brasileiro, segundo o Instituto Brasileiro de Geografia e Estatística (IBGE, 2014), as informações do PIB revelam o poder econômico de estados e municípios e a desigualdade ou concentração da renda. Ainda, segundo Teixeira (2009), o PIB pode ser considerado a melhor medida de desempenho econômico de uma nação, pois uma economia que disponha de grande produção de bens e serviços tem maior potencial de atender às demandas de indivíduos, empresas e governos.

As transferências de recursos da União para estados, Distrito Federal e municípios aumentaram em mais de $136 \%$ entre meados dos anos 1990 e 2006, como consequência da ampliação da descentralização das políticas públicas (Garcia, 2015). Todavia, muitas despesas, principalmente nas áreas em que há elevado peso na produção de bens e serviços entregues à sociedade, não são feitas com a eficácia esperada, sendo necessária a adoção de métodos adequados de avaliação e de prestação de contas que se coadunem com o aumento do desempenho das políticas públicas (Olivieri, 2010; Pollitt e Bouckaert, 2011). Além disso, existe, ainda, a necessidade de direcionar os recursos para regiões mais carentes e prioritárias, com base em critérios impessoais, legais e de justiça social, o que muitas vezes não ocorre na prática. $\mathrm{Na}$ ausência de fatores adequados a articulação e coordenação das decisões e execução dos investimentos, predominam a pulverização e o clientelismo, facilitados pela dispersão de recursos e poucos esforços de aplicação eficiente (Silva e Costa, 1995). 
As transferências fiscais intergovernamentais podem atender ao primeiro objetivo de cumprir com os requisitos legais e constitucionais de devolução tributária. Uma segunda finalidade é a de reduzir disparidades e diferenças de arrecadação entre as regiões geopolíticas, dotando os entes com menor poder de arrecadação tributária de recursos suplementares, aproximando-se do perfil de transferência do tipo redistributiva. Podem, ainda, ter como finalidade a viabilização de políticas setoriais, caracterizando-se como transferências condicionadas a determinados objetivos definidos pelos governos dos níveis superiores. Nesses casos, a centralização dos recursos é feita pelo governo federal, mas a execução do gasto ocorre de forma descentralizada, exigindo como condicionantes do governo local uma restrição de gasto por setor/programa ou a devolução de uma contrapartida financeira com recursos próprios. Apesar de a primeira categoria ser bem definida (devolução de tributos), a delimitação entre as outras duas finalidades não é sempre exequível, pois os objetivos de equalização (escopo das transferências redistributivas) podem ser perseguidos pelas transferências setoriais (Prado, Quadros e Cavalcanti, 2003).

Sendo também denominadas transferências discricionárias ou negociadas, as transferências voluntárias podem ser, a priori, utilizadas pelo governo federal para a função redistributiva ou para a execução de políticas setoriais. Não obstante, sendo oriundas do Orçamento Geral da União (OGU), a materialização dessas transferências pode ter como principal objetivo a barganha política (Arretche e Rodden, 2004).

O planejamento orçamentário - por meio da tríade Plano Plurianual (PPA), Lei de
Diretrizes Orçamentárias (LDO) e Lei Orçamentária Anual (LOA) - é uma iniciativa privativa do Poder Executivo, sendo submetido posteriormente à apreciação do Poder Legislativo (Pares e Valle, 2006). Nesse processo, as transferências voluntárias são definidas, inicialmente, na elaboração do Projeto de Lei Orçamentária Anual (Ploa) pelo Poder Executivo e, após este ser enviado ao Congresso Nacional, aquelas sofrem novas inclusões ou alterações por meio das emendas parlamentares. No processo de execução orçamentária, o Poder Executivo tem liberdade para efetuar ou não as despesas, já que a LOA consiste em uma autorização, e não imposição, para a execução de gastos (estando sujeita a contingenciamentos). Assim, atores políticos diversos empenham-se numa maratona para conseguir, por meio de barganha, efetivar as transferências voluntárias inseridas no orçamento (Miranda Soares e Guimarães De Melo, 2016).

Conforme o Plano Nacional de Saneamento Básico - Plansab (Brasil, 2014), os repasses da União (transferências voluntárias) podem ser caracterizados como recursos não onerosos (oriundos do OGU), os quais não preveem retorno financeiro direto dos investimentos, uma vez que os beneficiários de tal recurso necessitam desembolsar apenas o valor da contrapartida financeira. A quantia dessa contrapartida, segundo Miranda Soares e Guimarães de Melo (2016), geralmente é estabelecida pela LDO, em percentual que considera a população e a localização regional.

O Tribunal de Contas da União (TCU) menciona duas formas de origem dos recursos para as transferências voluntárias alocadas a partir do OGU: 1) contemplação nominal do Estado, do município ou da ONG, por meio da proposta do Executivo ou de emenda 
parlamentar ao Orçamento da União por deputado federal ou senador; ou 2) não há uma contemplação explícita, mas o programa orçamentário destina recursos para a região onde se localiza o pretendente e prevê a aplicação por meio de órgão ou entidade estadual, municipal ou não governamental (Brasil, 2013, p. 18).

\section{Procedimentos metodológicos}

A coleta de dados foi realizada por meio de um estudo exploratório, de natureza qualitativa. Foram adotados, como grupo específico, os 39 municípios da RMSP. A escolha dessa área foi intencional, devido à existência de pesquisas sobre o tema em alguns desses municípios e por se localizarem na região mais rica, populosa e industrializada do País, gerando grande volume de resíduos sólidos decorrente do consumo e descarte.

Uma vez definida a área de estudo, o levantamento de dados incidiu sobre duas variáveis: 1) os repasses do governo federal e 2) os resultados relacionados ao desempenho no uso desses repasses pelos municípios beneficiados.

Para a obtenção dos dados sobre os repasses, foram consultados os seguintes documentos: o Plano Plurianual (PPA) 20042007, 2008-2011 e 2012-2015; e a Lei Orçamentária Anual (LOA), incluindo o anexo "Volume II: consolidação dos programas de governo", entre 2004-2015, ${ }^{1}$ concentrando-se nos programas Resíduos Sólidos Urbanos (8007) e Resíduos Sólidos (2067). Essas informações estão organizadas no Quadro 1. É importante mencionar que, embora no Portal da Transparência existam muitas outras ações orçamentárias relativas à gestão de resíduos sólidos, no Quadro 1 foram apresentadas apenas as que tiveram, dentre seus beneficiados, os municípios da RMSP.

Posteriormente, foi realizada consulta no Portal da Transparência para identificar, a na aba "programa de governo" no ano (20042015), os repasses para as ações dos respectivos programas mencionados nos PPAs. Foi iniciada a busca a partir do ano de 2004 por não haver informações de anos anteriores. Desses repasses, utilizaram-se dois filtros: 1 ) beneficiados somente do estado de São Paulo; e 2) quais desses eram os municípios localizados na RMSP e que receberam recursos para ações relacionadas aos resíduos sólidos. Após a identificação dos municípios beneficiados, foram verificadas, no Portal da Transparência, as informações e os detalhamento sobre os repasses, incluindo o tipo de transferência, os órgãos federais concedentes ou contratantes, os valores recebidos pelos municípios, o objeto dos repasses e o período de vigência do convênio/contrato de repasse. Essas informações foram complementadas através do website da Caixa, ${ }^{2}$ do Diário Oficial da União (DOU) e do Portal de Convênios. ${ }^{3}$

Para analisar os resultados das transferências desses recursos sobre a atuação dos municípios no manejo de RSU, foram elaborados indicadores que permitiram mensurar esses resultados, a partir das informações sobre as variáveis coleta seletiva, quantidade de materiais recuperados após a triagem e quantidade de galpões de triagem, com base nos anexos do "Diagnóstico do manejo de resíduos sólidos urbanos", disponibilizados pelo SNIS. ${ }^{4}$ Esse sistema é administrado pela Secretaria Nacional de Saneamento Ambiental (SNSA), órgão vinculado ao antigo MCidades. $O$ Quadro 2 apresenta as variáveis utilizadas e os indicadores adotados. 
Quadro 1 - Objetivos dos programas descritos nos PPAs sobre resíduos sólidos e as respectivas ações orçamentárias do governo federal

\begin{tabular}{|c|c|c|}
\hline $\begin{array}{l}\text { Programa } \\
\text { de governo }\end{array}$ & Objetivo & $\begin{array}{l}\text { Ações } \\
\text { orçamentárias } \\
\text { identificadas }\end{array}$ \\
\hline $\begin{array}{l}\text { Programa 8007: } \\
\text { Resíduos Sólidos } \\
\text { Urbanos (PPA 2004- } \\
2007 \text { e PPA 2008-2011) }\end{array}$ & $\begin{array}{l}\text { "Ampliar a área de cobertura e eficiência dos serviços públicos de manejo } \\
\text { de resíduos sólidos, com ênfase no encerramento de lixões, na redução, } \\
\text { no reaproveitamento e na reciclagem de materiais, por meio da inclusão } \\
\text { socioeconômica de catadores". }\end{array}$ & \multirow{3}{*}{8274 (a) } \\
\hline \multirow{2}{*}{$\begin{array}{l}\text { Programa 2067: } \\
\text { Resíduos Sólidos (PPA } \\
\text { 2012-2015) }\end{array}$} & $\begin{array}{l}\text { "Ampliar o acesso aos serviços de manejo de resíduos sólidos urbanos de forma } \\
\text { ambientalmente adequada, induzindo a gestão consorciada dos serviços e a } \\
\text { inclusão socioeconômica de catadores de materiais recicláveis". }\end{array}$ & \\
\hline & $\begin{array}{l}\text { "Promover a implementação da Política Nacional de Resíduos Sólidos } \\
\text { com ênfase na reestruturação das cadeias produtivas, na integração das } \\
\text { associações, cooperativas e redes de cooperação de catadores, na estruturação } \\
\text { do planejamento do setor, no gerenciamento de áreas contaminadas e na } \\
\text { inovação tecnológica respeitando as peculiaridades regionais". }\end{array}$ & \\
\hline
\end{tabular}

Nota: dentre os repasses da ação orçamentária 8274, os beneficiados foram somente cooperativas, porém houve uma exceção, com o repasse para a prefeitura de Osasco, sendo incluído na análise.

Fonte: elaboração própria, a partir da consulta nos PPAs 2004-2007, 2008-2011, 2012-2015 e Portal da Transparência.

Quadro 2 - Identificação e seleção das variáveis nos objetivos dos Programas dos PPAs e a definição operacional para mensurá-las

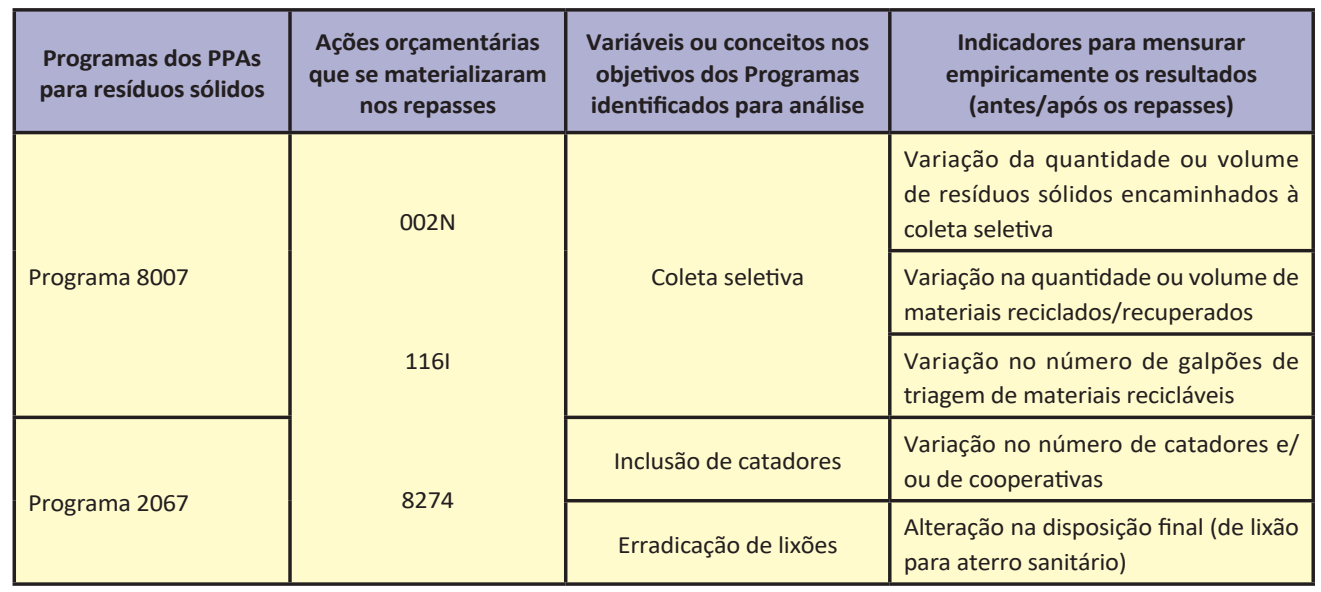

Fonte: elaboração própria. 
Também foram analisadas as informações sobre o início e o término do convênio ou do contrato de repasses, considerando: 1) se os municípios receberam integralmente os valores informados nos convênios ou contrato de repasse; e 2) em que ano ocorreram as transferências. Esta última informação é relevante, pois é necessário um tempo de maturação entre o repasse e o resultado esperado para o município: aumento da cobertura da coleta seletiva e da taxa de reciclagem. Tendo sido identificados, os repasses foram atualizados a partir do ano subsequente do repasse (valor liberado) até o mês de dezembro de 2016, através do Índice Geral de Preços do Mercado (IGP-M), calculado através do site do Banco Central. ${ }^{5}$

É importante ressaltar que as informações sobre os valores dos repasses apresentaram divergências em alguns municípios. Houve dois convênios Siafi (Sistema Integrado de Administração Financeira) firmados pela Funasa, sendo um para o município de Osasco (557775) e outro para Taboão da Serra (558057), que não foram considerados neste estudo, em virtude da ausência de informações sobre liberação dos respectivos valores no Portal da Transparência e no Portal dos Convênios.

Também se identificaram algumas divergências nos valores informados entre as fontes consultadas nos casos dos contratos de repasse (CTR) dos municípios de Embu das Artes (CTR 0254805-86) e em São Paulo (CTR 0254829-62), ambos firmados com a Caixa. Apesar disso, esses repasses foram incluídos entre os dados analisados por este estudo, priorizando-se os dados disponíveis no Portal da Transparência ou Portal dos Convênios e, complementarmente, pelas informações do DOU e da Caixa.
Municípios

\section{da RMSP beneficiados, objeto dos repasses e a capacidade econômica}

O Quadro 3 apresenta as informações sobre os recursos que foram transferidos pelo governo federal, os municípios beneficiados, o objeto dos repasses e os órgãos responsáveis pelas transferências.

Entre os principais resultados esperados das transferências do governo federal aos municípios seriam a adoção ou ampliação do serviço de coleta seletiva, a taxa de reciclagem de resíduos e a inclusão dos catadores nos sistemas de gestão integrada de resíduos sólidos dos municípios analisados, corroborado, inclusive, pelas próprias informações sobre o objeto dos repasses destacado no Quadro 3. Ao mesmo tempo, os programas dos PPAs do governo federal informados no Quadro 1 colocam como dois principais objetivos: 1) a prioridade à hierarquia da gestão de resíduos sólidos urbanos: redução, reaproveitamento e reciclagem de resíduos sólidos, com a inclusão dos catadores; e 2) a erradicação dos lixões.

Considerando que, pelo menos desde 2005, nenhum dos municípios beneficiados da RMSP destinava resíduos sólidos para lixões (Cetesb, 2006), os repasses federais deveriam atender aos objetivos relacionados a reciclagem e inclusão de catadores, cujos valores são apresentados na Figura 1, com atualização monetária até o final de 2016.

Ao considerar-se a situação econômica como critério relevante para a alocação desses recursos, a Figura 2 relaciona o PIB per capita dos municípios beneficiados com a média 
Quadro 3-Informações sobre as transferências voluntárias e os municípios beneficiados da RMSP

\begin{tabular}{|l|c|c|l|}
\hline \multirow{2}{*}{ Municípios beneficiados } & \multicolumn{2}{c|}{ Informações sobre as transferências voluntárias } \\
\cline { 2 - 4 } & Órgão superior & Órgão concedente & \multicolumn{2}{c|}{ Objeto dos repasses } \\
\hline $\begin{array}{l}\text { Mogi das Cruzes, Osasco, Mairiporã e Taboão } \\
\text { da Serra }\end{array}$ & MS & Funasa & Sistema de resíduos sólidos \\
\hline $\begin{array}{l}\text { Diadema, Embu das Artes, Francisco Morato, } \\
\text { Franco da Rocha, Itapecerica da Serra, Ribeirão } \\
\text { Pires, Santo André, São Paulo e Taboão da Serra }\end{array}$ & MCidades & Caixa & $\begin{array}{l}\text { Construção de galpão de } \\
\text { triagem para catadores }\end{array}$ \\
\hline Osasco & MTE & SNES & $\begin{array}{l}\text { Apoio à organização de } \\
\text { catadores para geração de } \\
\text { trabalho e renda }\end{array}$ \\
\hline
\end{tabular}

Fonte: elaboração própria a partir dos dados do Portal da Transparência do governo federal.

Notas: MS: Ministério da Saúde; MCidades: Ministério das Cidades; MTE: Ministério do Trabalho e Emprego; SNES:

Secretaria Nacional de Economia Solidária.

Observação: o MTE e o MCidades foram extintos em 2019 pelo atual presidente Jair Bolsonaro.

Figura 1 - Valores das transferências voluntárias liberados e atualizados para os municípios beneficiados da RMSP (em R\$) - atualizados até 2016

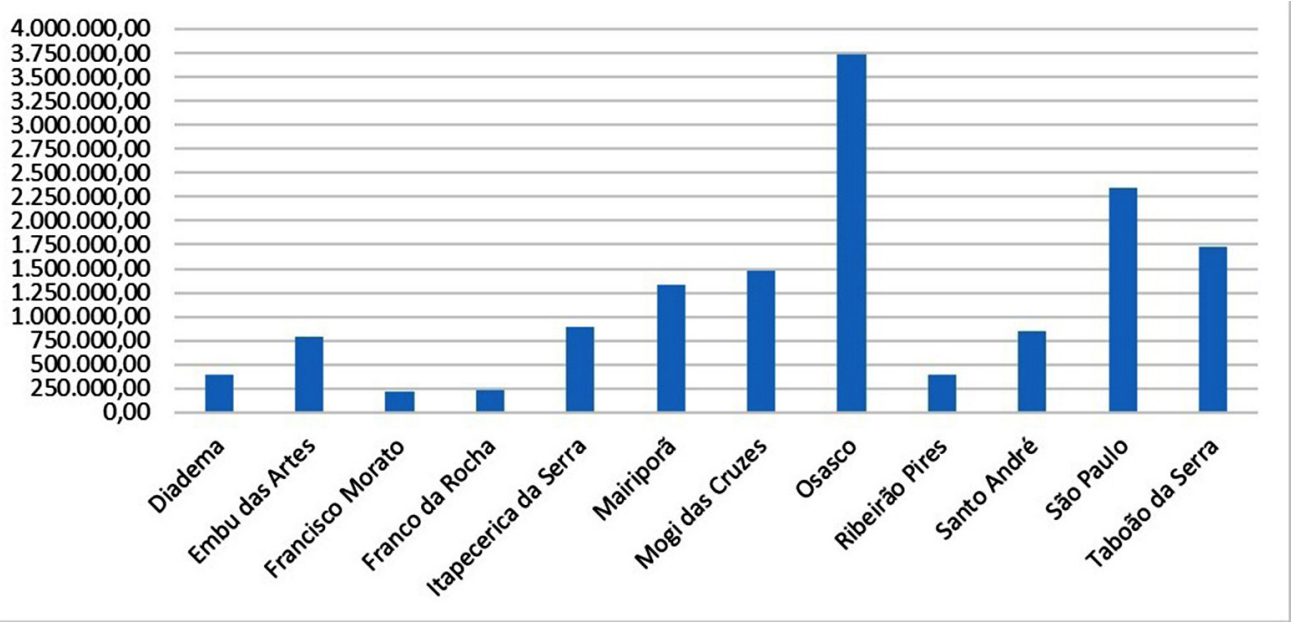

Fonte: elaboração própria a partir do Portal da Transparência, Diário Oficial da União (DOU), website da Caixa e Portal dos Convênios. 
Figura 2 - PIB per capita dos municípios da RMSP, em 2012, beneficiados pelos repasses do governo federal comparados com a média nacional (em $\mathrm{R} \$$ )

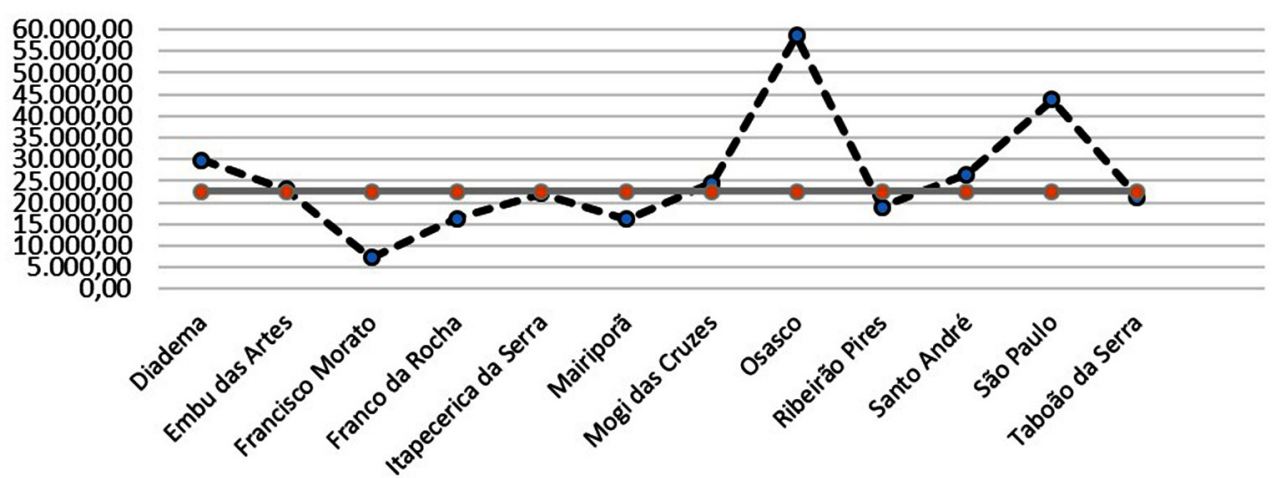

- 0 - PIB per capita dos municípios em 2012

Fonte: elaboração própria a partir do IBGE Cidades (PIB per capita dos municípios) e informações sobre a média da renda per capita nacional pelo IBGE (2014).

nacional. Se considerarmos que essas transferências têm (ou deveriam ter) como propósito auxiliar municípios com baixa capacidade financeira, reduzindo, assim, as disparidades do federalismo brasileiro (Furtado, 1999), era de se supor que os municípios com PIB acima e próximos da média nacional fossem a última opção do governo federal.

A partir do agrupamento dos repasses fiscais para grupos de municípios, conforme o nível do PIB per capita (Figura 3), é possível constatar que a concentração desses repasses foi justamente para os municípios com alto e médio nível econômico, numa clara política de "Robin Hood" às avessas. A prioridade para esses municípios atua no sentido de manter as desigualdades regionais e locais.
A alocação desses repasses para municípios com elevada capacidade econômica não é coerente com os objetivos da Lei de Diretrizes Nacionais para o Saneamento Básico (LDNSB, lei federal n. 11.445/2007), que seriam: a redução das desigualdades regionais e a prioridade de ações que visem à ampliação do saneamento básico para populações de baixa renda, sendo também enfatizado pelo Plansab (Brasil, 2014). Apesar de a RMSP apresentar indicadores de cobertura para os serviços de saneamento básico acima da média nacional, essa região possui significativas diferenças na densidade populacional, distribuição de renda e no acesso à infraestrutura urbana em cada município e entre os municípios. Pasternak e Bógus (2011) identificaram diferenças 
Figura 3 - Distribuição dos repasses do governo federal por grupos de municípios de acordo com o PIB per capita - 2012

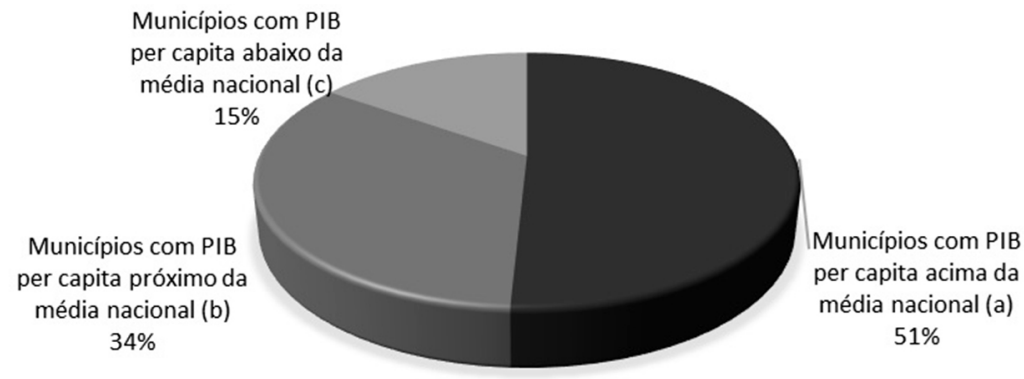

Fonte: elaboração própria a partir das informações do Portal da Transparência, Portal dos Convênios e site da Caixa. Notas: (a) Diadema, Osasco, Santo André e São Paulo; (b) Embu das Artes, Itapecerica da Serra, Mogi das Cruzes e Taboão da Serra; (c) Francisco Morato, Franco da Rocha, Mairiporã e Ribeirão Pires.

relevantes no acesso à água potável e na rede de esgotamento sanitário entre os domicílios dos diferentes municípios da RMSP: as parcelas mais pobres da população metropolitana localizavam-se nos municípios com faixas menores de cobertura desses serviços.

Ao mesmo tempo, embora não tenha sido possível identificar a origem dessas transferências (emenda parlamentar ou seleção realizada diretamente pelos órgãos concedentes) e os critérios de escolha (recursos obtidos pela adequação dos requisitos técnicos do solicitante ou por barganha política), o fato é que a tendência nacional para as transferências voluntárias tem sido a seleção justamente dos municípios com maior capacidade econômica e populosos. Arretche e Rodden (2004, p. 566), ao analisar o aspecto redistributivo das transferências intergovernamentais não constitucionais, por meio do PIB per capita estadual, identificaram que os menos beneficiados são os municípios e regiões mais pobres: "[...] quanto mais pobre o estado, menos ele recebe". De maneira similar, Miranda Soares e Guimarães de Melo (2016) observaram que os municípios mais ricos (incluindo as capitais estaduais) e com maior arrecadação tributária foram mais beneficiados com recursos das transferências voluntárias. Não há estudos que apontem as razões dessa desigualdade, mas pode-se aventar as hipóteses de que elas se devam a fatores políticos (deputados/senadores de algumas regiões conseguem incluir emendas ao orçamento beneficiando suas regiões/estados), 
técnicos (regiões mais ricas já detêm recursos humanos, técnicos e financeiros suficientes para dar andamento mais rápido ou efetivo a projetos) ou uma conjunção deles.

\section{Resultados da coleta seletiva e investimentos potenciais pelos repasses do governo federal}

0 reaproveitamento e a reciclagem de resíduos sólidos, diretamente umbilicados com a gestão integrada preconizada pela PNRS, compreendem três grupos de atores sociais: 1) as autoridades públicas que estabelecem as políticas públicas para a gestão de resíduos e a tributação da cadeia produtiva; 2) a população que deve estar ciente dos benefícios da prevenção, da segregação dos materiais, da reciclagem e da eliminação de resíduos; e 3) o setor privado, através da cadeia de produção, que pode desenvolver estratégias e táticas para administrar o processo de gerenciamento de resíduos recicláveis (Chen, Geng e Fujita, 2010). Ainda cabe destacar que, no contexto latino americano, as cooperativas de catadores tornaram-se um importante elo entre as autoridades públicas, a população e o setor privado para a consolidação da gestão integrada de resíduos sólidos (Cherfem, 2015; Zanta, 2009).

Para analisar os possíveis resultados sobre a variação da coleta seletiva e da inclusão dos catadores antes/após as transferências do governo federal, tornou-se necessário verificar o potencial de aplicação do investimento propiciado por esses repasses, conforme apresentados no Quadro 4.

Quadro 4 - Descrição dos valores, componentes e produtividade previstos para galpão de triagem de grande ou médio porte

\begin{tabular}{|c|c|c|}
\hline \multirow{2}{*}{$\begin{array}{l}\text { Informações sobre o processamento de resíduos } \\
\text { e número de catadores potencialmente empregados }\end{array}$} & \multicolumn{2}{|c|}{ Tipo e tamanho do galpão de triagem } \\
\hline & $\begin{array}{l}\text { Grande porte } \\
\left(1.000 \mathrm{~m}^{2}\right)\end{array}$ & $\begin{array}{l}\text { Médio porte } \\
\left(550 \mathrm{~m}^{2}\right)^{* *}\end{array}$ \\
\hline Capacidade de triagem e gerenciamento (t/ano) & 3.600 & 1.800 \\
\hline Número de catadores empregados & 160 & 80 \\
\hline Produtividade (t/catador.ano ${ }^{-1}$ ) & 22,5 & 22,5 \\
\hline Requerimento total de área para estrutura física e estacionamento $\left(\mathrm{m}^{2}\right)^{*}$ & 2.000 & 1.000 \\
\hline $\begin{array}{l}\text { Valor total do investimento para } 2016 \text {, incluindo estrutura física, } \\
\text { equipamentos e capacitação dos catadores (R\$) }\end{array}$ & $1.254 .350,72$ & $770.578,67$ \\
\hline
\end{tabular}

Fonte: elaboração própria a partir do Ministério do Desenvolvimento Social e Combate à Fome - MDS (Brasil, 2006). Notas: *Segundo o MDS, além da área para a estrutura física, é necessária uma outra área do mesmo tamanho para estacionamento de veículos e carregamento dos fardos.

**Valores e quantidade de componentes para galpão médio foram adaptados a partir da descrição feita pelo MDS para galpão grande. 
Tendo sido identificados os valores recebidos pelos municípios e os custos de investimento para a construção física dos galpões de triagem e aquisição dos equipamentos, apurou-se a abrangência do programa de coleta seletiva, cujos indicadores são apresentados na Tabela 1, incluindo a quantidade de materiais recuperados/reciclados pela coleta seletiva antes e após as transferências (excetuado Mairiporã que não participou de nenhuma das pesquisas do SNIS nos anos perquiridos). Também é importante destacar que, em alguns casos, não foi possível calcular a média dos anos 2008-2009 e 2015-2016, seja por discrepância nos valores informados, seja por ausência de informação.

Tabela 1 - indicadores sobre a variação da coleta seletiva, materiais recuperados e galpões de triagem nos municípios beneficiados da RMSP 2008-2009 e 2015-2016

\begin{tabular}{|c|c|c|c|c|c|c|c|c|}
\hline \multirow{2}{*}{ Município } & \multicolumn{3}{|c|}{$\begin{array}{l}\text { Coleta seletiva } \\
\qquad(\mathrm{Cs026)}\end{array}$} & \multicolumn{3}{|c|}{$\begin{array}{l}\text { Materiais recuperados após triagem } \\
\qquad(\text { Cs009) }\end{array}$} & \multicolumn{2}{|c|}{$\begin{array}{l}\text { Quantidade de } \\
\text { galpões de triagem } \\
\text { (Up003 e Up004) }\end{array}$} \\
\hline & $\begin{array}{c}\text { Média } \\
\text { 2008-2009 } \\
\text { (t/ano) }\end{array}$ & $\begin{array}{c}\text { Média } \\
\text { 2015-2016 } \\
\text { (t/ano) }\end{array}$ & $\begin{array}{l}\text { Variação } \\
\text { (\%) }\end{array}$ & $\begin{array}{l}\text { Média } \\
\text { 2008-2009 } \\
\text { (t/ano) }\end{array}$ & $\begin{array}{c}\text { Média } \\
\text { 2015-2016 } \\
\text { (t/ano) }\end{array}$ & $\begin{array}{l}\text { Variação } \\
\text { (\%) }\end{array}$ & 2008 & 2016 \\
\hline Diadema & $1.267,5$ & $1.258,0$ & $(-) 0,8$ & $1.193,0$ & SI & - & 01 & 01 \\
\hline Embu das Artes & $1.949,5$ & $2.400,0(d)$ & 23,1 & 936,0 & $1.700,3$ & 81,6 & $\mathrm{SI}$ & 01 \\
\hline Francisco Morato & NP & 0 & - & NP & 0 & - & NP & SI \\
\hline Franco da Rocha & SI & $1.920,0$ (c) & - & SI & $1.316,0$ (c) & - & SI & $\mathrm{SI}$ \\
\hline Itapecerica da Serra & 575,5 & 698,0 & 21,3 & 505,0 & 546 & 8,1 & 01 & 01 \\
\hline Mogi das Cruzes & $873,0(a)$ & $5.241,5$ & 500,4 & 789,0 & $3.700,5$ & 369 & SI & $\mathrm{SI}$ \\
\hline Osasco & 757,0 & $1.346,4$ (c) & 77,8 & 657,0 & $1.345,4$ (c) & 104,8 & SI & 03 \\
\hline Ribeirão Pires & (b) & 218,8 & - & (b) & 168,3 & - & $\mathrm{SI}$ & 01 \\
\hline Santo André & $6.274,5$ & $12.917,0$ & 105,9 & $1.840,0$ & $2.183,0$ & 18,6 & 02 & 02 \\
\hline São Paulo & $37.605,0$ & $86.366,0$ & 129,7 & $26.323,5$ & $47.667,4$ (c) & 81,1 & 15 & $26(c)$ \\
\hline Taboão da Serra & $\mathrm{IE}$ & 700,0 & - & IE & 665 & - & SI & SI \\
\hline
\end{tabular}

Fonte: elaboração própria a partir das informações do SNIS pelos códigos Cs026, Cs009, Up003 e Up004.

(a) Por possíveis erros de preenchimento (ausência de informação, discrepância ou divergência nos valores informados), foram consideradas somente as informações de 2009.

(b) Não há informações para 2008; em 2009, informa valor de 197.807 toneladas (cinco vezes acima do volume recoIhido por São Paulo). Por isso, foi excluído da análise.

(c) Por possíveis erros de preenchimento (ausência de informação, discrepância ou divergência nos valores informados), foram consideradas somente as informações de 2015.

(d) Por possíveis erros de preenchimento (ausência de informação, discrepância ou divergência nos valores informados), foram consideradas somente as informações de 2016.

SI: sem informação, embora tenha participado da pesquisa do SNIS.

NP: não participante da pesquisa do SNIS no ano de referência.

IE: informação excluída: o município informa apenas 10 t para todo o ano de 2009, o que corresponde a menos de 1 t/mês. É possível que tenha havido um erro de preenchimento. Optou-se por excluir essa informação. 
É possível identificar alguns municípios que tiveram pouca alteração (ou mesmo redução) nos resultados da coleta seletiva e/ ou da taxa de reciclagem entre os períodos analisados. Destacam-se Diadema, Itapecerica da Serra e Santo André. Diadema apresentou uma redução da coleta seletiva de quase $1 \%$. Itapecerica da Serra demonstrou pequena alteração no período, seja para a coleta seletiva (aumento de $21 \%$ ), seja para a recuperação de materiais recicláveis após a triagem (aumento de $8 \%$ ). Por último, Santo André apresentou uma situação atípica: houve um significativo aumento nos resultados da coleta seletiva (quase $106 \%$ ), mas, ao mesmo tempo, a recuperação de materiais recicláveis foi de apenas $18 \%$. Apesar das dúvidas quanto a qualidade, veracidade e consistência dos dados presentes no SNIS, no período analisado, Santo André não declarou nenhuma variação no número de galpões de triagem. Logo, o aumento expressivo da abrangência do programa de coleta seletiva pode ser uma consequência do uso preponderante de veículos compactadores pelas empresas contratadas pelo município. Em cidades como Santo André e São Paulo, um estudo da Funasa revelou o uso maciço desse tipo de veículo que, por compactar os resíduos recicláveis, reduz a qualidade na segregação do material e seu potencial para reciclagem (Brasil, 2010a).

Outros municípios revelaram aumento significativo na coleta seletiva e, sobretudo, na reciclagem de resíduos sólidos. Enquadram-se, nesse grupo, Embu das Artes (quase $82 \%$ na recuperação de materiais recicláveis), Mogi das Cruzes (acima de 500\% na coleta seletiva e 369\% na recuperação de materiais recicláveis), Osasco (aproximadamente $78 \%$ na coleta seletiva e $105 \%$ na recuperação de materiais recicláveis) e São Paulo (cerca de 130\% na coleta seletiva e próximo a $81 \%$ na recuperação de materiais recicláveis).

Esses indicadores apontam que alguns municípios tiveram aumentos na abrangência dos programas de coleta seletiva e na quantidade de materiais recuperados/reciclados. Mas esses aumentos atingiram o que era esperado com a aplicação dos recursos federais? 0 Quadro 5 faz uma comparação entre o resultado previsto desses recursos federais versus o resultado real obtido sobre a coleta seletiva e a reciclagem executadas pelos municípios.

Apesar de uma aparente melhora nos indicadores sobre a reciclagem de resíduos por meio da coleta seletiva, com exceção de São Paulo e Mogi das Cruzes (a priori), os demais municípios não atingiram a quantidade esperada com a aplicação eficiente dos recursos federais. Embora nos municípios de Diadema, Franco da Rocha e Ribeirão Pires fossem necessárias complementações financeiras com recursos próprios, municípios como Osasco e Taboão da Serra apresentaram os piores déficits, sendo justamente os que firmaram mais de um convênio/contrato de repasse com o governo federal para o mesmo objeto, com valores elevados para a construção de galpões de triagem (parâmetro utilizado para análise). Pode-se ainda incluir o caso de Francisco Morato que, mesmo recebendo repasses federais, não possui o serviço de coleta seletiva e unidade para triagem de materiais recicláveis.

Alguns desses municípios também não demonstraram aumento no número de galpões de triagem de resíduos sólidos após as transferências. É o caso de Diadema, que apresenta somente uma unidade existente desde 2000; Embu das Artes com uma unidade desde 1994; Ribeirão Pires com uma unidade desde 
Quadro 5 - Comparativo entre a quantidade recuperada de recicláveis prevista com os recursos federais e a quantidade efetivamente obtida pelos municípios da RMSP analisados - 2015-2016

\begin{tabular}{|c|c|c|c|c|c|c|}
\hline \multirow[b]{2}{*}{ Município } & \multicolumn{2}{|c|}{ Período (ano) } & \multirow[b]{2}{*}{$\begin{array}{l}\text { Características do galpão de triagem com } \\
\text { base nos recursos das transferências }\end{array}$} & \multicolumn{3}{|c|}{ Quantidade de resíduos (em $\mathrm{t} / \mathrm{ano}$ ) } \\
\hline & $\begin{array}{l}\text { Formalização } \\
\text { do CV ou } \\
\text { CTR }\end{array}$ & $\begin{array}{l}\text { Liberação } \\
\text { dos valores* }\end{array}$ & & $\begin{array}{l}\text { Previsto para a } \\
\text { reciclagem com } \\
\text { a aplicação das } \\
\text { transferências (a) }\end{array}$ & $\begin{array}{l}\text { Efetivamente } \\
\text { reciclados } \\
\text { pela média de } \\
2015-2016\end{array}$ & $\begin{array}{l}\text { Desempenho } \\
\text { previsto } \\
\text { versus obtido }\end{array}$ \\
\hline Diadema & 2008 & 2012 & $\begin{array}{l}\text { Recursos insuficientes para } 1 \text { galpão médio } \\
\text { (necessária a complementação com recurso } \\
\text { próprio) }\end{array}$ & $2.993,0$ & $1.258,0$ (c) & $(-) 1.735,0$ \\
\hline Embu das Artes & 2008 & 2012 & Recursos suficientes para 1 galpão médio & $2.736,0$ & $1.700,3$ & $(-) 1.035,7$ \\
\hline Franco da Rocha & 2008 & 2011 e 2012 & $\begin{array}{l}\text { Recursos insuficientes para } 1 \text { galpão médio } \\
\text { (necessária a complementação com recurso } \\
\text { próprio) }\end{array}$ & $1.800,0(b)$ & $1.316,0(d)$ & $(-) 484$ \\
\hline Itapecerica da Serra & 2008 & 2012 & Recursos suficientes para 1 galpão médio & $2.305,0$ & 546 & $(-) 1.759$ \\
\hline Mogi das Cruzes & 2004 & 2005 & $\begin{array}{l}\text { Recursos suficientes para } 1 \text { galpão grande, } \\
\text { além de excedente acima de } 220 \text { mil reais }\end{array}$ & $3.600,0(b)$ & $3.700,5$ & 100,5 \\
\hline Osasco & 2005 e 2011 & 2007 e 2011 & $\begin{array}{l}\text { Recursos suficientes para } \\
\text { aproximadamente } 3 \text { galpões grandes }\end{array}$ & $10.800,0(b)$ & $1.345,4(d)$ & $(-) 9.454,6$ \\
\hline Ribeirão Pires & 2008 & 2011 & $\begin{array}{l}\text { Recursos insuficientes para } 1 \text { galpão médio } \\
\text { (necessária a complementação com recurso } \\
\text { próprio) }\end{array}$ & $1.800,0(b)$ & 168,3 & $(-) 1.631,7$ \\
\hline Santo André & 2008 & 2011 & Recursos suficientes para 1 galpão médio & $3.640,0$ & $2.183,0$ & $(-) 1.457$ \\
\hline São Paulo & 2008 & 2011 & $\begin{array}{l}\text { Recurso praticamente suficientes para } 2 \\
\text { galpões grandes }\end{array}$ & $33.523,5$ & $47.667,4$ (d) & $14.143,9$ \\
\hline Taboão da Serra & 2005 e 2008 & 2008 e 2011 & $\begin{array}{l}\text { Recurso suficiente para } 1 \text { galpão grande, } \\
\text { com um excedente próximo de } 470 \text { mil } \\
\text { reais }\end{array}$ & $3.600(b)$ & 665 & $(-) 2.935$ \\
\hline
\end{tabular}

Fonte: elaboração própria a partir das informações do Snis, Portal da Transparência, Portal dos Convênios, Diário Oficial da União e website da Caixa.

Notas: *refere-se ao valor total ou predominantemente liberado no ano; (a) soma da média de materiais recuperados entre 2008-2009 (antes das transferências) com os investimentos previstos supostamente já executados entre 2015-2016; b) considerou-se apenas os investimentos previstos pelos recursos federais, não incluindo o que os municípios já reciclavam (supostamente) antes das transferências; (c) excepcionalmente, utilizou-se a quantidade de resíduos recolhidos pela coleta seletiva; (d) por possíveis erros de preenchimento, utilizou-se somente as informações de 2015; CV - convênio; CTR - contrato de repasse.

2004; e Santo André, com duas unidades em operação desde 1999-2000. É possível que os demais também não tenham alterado o número de galpões, embora não tenha sido possível averiguar essa informação pelo SNIS.

No caso de São Paulo, não é possível afirmar que o aumento da quantidade de resíduos reciclados e do número de galpões de triagem ocorreu com a inclusão dos catadores de materiais recicláveis, como demandam os objetivos dos PPAs do governo federal.
Klein (2017) identificou que, nesse município, foram inauguradas duas centrais mecanizadas de triagem (CMTs) em 2014, havendo, paralelamente, uma redução no volume de resíduos gerenciados pelas unidades de triagem não mecanizadas (objeto dos repasses do governo federal), impactando na redução da comercialização desses materiais pelas cooperativas de catadores e no aumento da ociosidade das unidades com triagem manual. E, no caso de Mogi das Cruzes, o estudo de Klein 
(ibid.) também aponta que a quantidade informada de resíduos reciclados é incompatível com a capacidade da única unidade de triagem existente no município. Isso é corroborado, inclusive, pelo Plano de Gestão Integrada de Resíduos Sólidos (PGIRS): “[...] um importante comentário é que a massa coletada é o dobro da capacidade da Usina de Triagem, ou seja, $50 \%$ do material recolhido na coleta seletiva tem sido destinado como lixo comum [rejeito]" (Mogi das Cruzes, 2013, p. 40; grifos nossos).

A prioridade do governo federal em transferir recursos para municípios da RMSP com maior capacidade financeira, mesmo considerando as divergências nas informações sobre valores transferidos, não refletiu em efetivos resultados de maneira a cumprir os objetivos dos PPAs (ampliação do serviço de coleta seletiva, aumento da reciclagem dos resíduos sólidos urbanos e da inclusão dos catadores na gestão municipal de resíduos sólidos), corroborando o diagnóstico de Silva e Costa (1995, p. 271) sobre o caráter "predatório" das transferências fiscais, baseadas na falta de controle e avaliação da aplicação efetiva desses recursos e contrariando os princípios de reduzir as desigualdades do federalismo brasileiro.

\section{Considerações finais}

Acerca da execução dos repasses, foi possível verificar algumas relevantes divergências entre as informações das transferências voluntárias divulgadas pelo Portal da Transparência, pelo Diário Oficial da União e pelo website da Caixa, podendo dificultar o próprio controle interno do governo federal sobre a efetividade no uso desses recursos. Além dessa limitação, foi possível notar que alguns municípios não informaram ao SNIS que receberam recursos federais. Também se constatou, em alguns beneficiados, a falta de clareza sobre o objeto dos repasses. Amalgamados, a falta de informação e a sua desarticulação entre os órgãos governamentais podem ser os principais fatores para os resultados modestos na abrangência dos serviços e no manejo de resíduos sólidos urbanos das municipalidades estudadas.

A ausência das informações produzidas pelos municípios irá comprometer a avaliação da efetividade das transferências voluntárias pelo governo federal. O Ministério do Meio Ambiente, a Funasa e a Caixa, principais órgãos responsáveis pelas transferências de recursos federais para programas de gestão municipal de resíduos sólidos urbanos, carecem de informações para identificar os municípios e as regiões prioritárias que necessitam de recursos financeiros e tecnológicos do governo federal para melhorar os resultados sobre a problemática dos RSU, em termos de interesse à saúde pública e nas questões ambientais. E também para nutrir os mecanismos de accountability, de forma que os órgãos responsáveis por tais tarefas tenham mecanismos para aferir se essas transferências tangenciam os procedimentos legais e se vêm sendo utilizadas com eficiência e efetividade, com vistas a uma gestão por resultados.

Foi possível identificar que a maior parte dessas transferências foi direcionada para municípios de elevado e médio PIB per capita, como Diadema, Osasco, Santo André e São Paulo. Como assinalado, a literatura aponta para a relevância no caráter redistributivo das transferências fiscais para reduzir a disparidade entre municípios e regiões (Prado, Quadros 
e Cavalcanti, 2003; Silva e Costa, 1995), princípio este também ressaltado pela LDNSB e pelo Plansab. Ao mesmo tempo, apesar do incentivo financeiro para "entrarem no jogo" das políticas federais, os municípios - em especial Diadema, Embu das Artes, Francisco Morato, Itapecerica da Serra, Osasco, Ribeirão Pires, Santo André e Taboão da Serra - não revelaram o desempenho esperado na taxa de reciclagem de resíduos sólidos e na inclusão dos catadores para gestão de resíduos sólidos urbanos quando comparados com o potencial de aplicação dos recursos recebidos.

Um ponto necessário a ser destacado é a enorme diversidade política, econômica, tecnológica e institucional nos mais de cinco mil municípios do País (Veloso et al., 2011). Em alguns casos, as municipalidades não possuem capacidades técnicas, recursos organizacionais e pessoal qualificado para universalizarem o saneamento básico, dependendo fortemente de aportes/transferências da União. Assim, se forem bem planejados e executados, esses repasses poderiam contribuir para reduzir tal diversidade de nosso federalismo e fortalecer a coordenação das políticas públicas entre os três entes federativos - União, estados e municípios. Caberia ao governo federal uma necessidade de reformulação nos atuais critérios das transferências voluntárias com vistas a uma gestão por resultados que busque: 1) reduzir das desigualdades regionais, priorizando municípios e regiões com menor capacidade financeira, tecnológica e institucional; 2) meIhorar os mecanismos de controle sobre os beneficiados; e 3) promover maior efetividade da coordenação intergovernamental, incluindo a produção, a divulgação e o compartilhamento de dados e informações.
Importante mencionar que as fontes consultadas não permitiram averiguar em qual dos dois caminhos se materializaram essas transferências fiscais. Um deles seria o atendimento de requisitos pelo Executivo municipal aos editais de chamamento público dos órgãos do governo federal (MMA, antigo MCidades, Funasa, entre outros), que disponibilizam recursos de dotações orçamentárias para a seleção pública de projetos nas áreas setoriais. 0 outro caminho seria o atendimento de requisitos pelo mesmo Executivo municipal aos órgãos do governo federal, porém, após aquele ter sido contemplado pelas emendas parlamentares. Ambos os percursos são oriundos do Orçamento Geral da União, embora possam ter diferentes critérios e requisitos para sua materialização. A forma de acesso (editais de chamamento público ou emendas parlamentares) é uma importante questão que pode influenciar na seleção dos beneficiados e no volume de recursos disponibilizados. Além disso, com a extinção do Ministério das Cidades e do Ministério do Trabalho, torna-se necessário verificar qual(is) ministério(s), órgão(s) e secretaria(s) continua(m) (ou não) incumbido(s) em promover as transferências voluntárias dos recursos federais para o objeto resíduos sólidos urbanos (RSU).

Sugerem-se outros estudos, inclusive em outras regiões do País e para outros componentes do saneamento básico, como água e esgotamento sanitário, que possam comparar se os beneficiados pelas transferências voluntárias possuem melhor capacidade técnica para atender aos requisitos nos editais públicos lançados pelos órgãos do governo federal. Ou, é possível que as emendas parlamentares, direcionando e selecionando municípios 
e regiões, possam reduzir o peso atribuído à competência técnica.

Estendendo o convite, seria relevante, também, outras pesquisas identificarem a distribuição dessas transferências em outros estados e regiões do País, comparando algumas variáveis, como PIB per capita, IDH e taxas de incidência de doenças associadas ao saneamento básico inadequado. Quer dizer, a tendência ao maior volume de recursos não onerosos para municípios mais abastados, como esta pesquisa identificou na RMSP, possui similaridade em outras regiões do País? E também para outros programas e ações que compõem o saneamento básico? São questões que merecem atenção.

\section{[1] https://orcid.org/0000-0002-3759-1460}

Universidade de São Paulo, Escola de Artes, Ciências e Humanidades, Núcleo de Pesquisa em Organizações, Sociedade e Sustentabilidade. São Paulo, SP/Brasil.

flabklein@gmail.com

\section{[II] http://orcid.org/0000-0001-6326-2129}

Universidade de São Paulo, Escola de Artes, Ciências e Humanidades, Programa de Pós-Graduação em Sustentabilidade; Instituto de Energia, Programa de Pós-Graduação em Ciência Ambiental. São Paulo, SP/Brasil.

sgdias@usp.br

\section{[III] https://orcid.org/0000-0001-9304-582X.}

Universidade de São Paulo, Escola de Artes, Ciências e Humanidades, Gestão de Políticas Públicas, Programa de Pós-Graduação em Gestão de Políticas Públicas. São Paulo, SP/Brasil.

cecilia.olivieri@usp.br

\section{Notas}

(1) Tais documentos foram obtidos através do site <www.orcamentofederal.gov.br>. Acesso em: 15 dez 2016.

(2) Disponível em: <https://webp.caixa.gov.br/urbanizacao/siurbn/acompanhamento/ac_publico/ sistema/asp/ptei_filtro_inicial.asp>. Acesso em: fev 2017.

(3) Disponível em: <http://portal.convenios.gov.br/>. Acesso em: fev 2017.

(4) Disponível em: <http://www.snis.gov.br/>. Acesso em: 2 mar 2017.

(5) Disponível em: <https://www3.bcb.gov.br/CALCIDADAO/publico/exibirFormCorrecaoValores.do? method=exibirFormCorrecaoValores>. Acesso em: 16 mar 2017. 


\section{Referências}

ABRUCIO, F. L. (2002). "Descentralização e coordenação federativa no Brasil: lições dos anos FHC". In: ABRUCIO, F. L. e LOUREIRO, M. R. (orgs.) O Estado numa era de reformas: os anos FHC - parte 2. Brasília, MP e Seges, pp. 143-246.

ALTVATER, E. (1995). O preço da riqueza. São Paulo, Editora da Universidade Estadual Paulista.

ARAÚJO, S. M. V. G. (2012). Lei dos resíduos sólidos e aprendizado político. In: CONGRESO LATINOAMERICANO DE CIENCIA POLÍTICA, 6, 2012, Quito. Anais... Quito, Asociación Latinoamericana de Ciencia Política (Alacip), pp. 1-18.

ARRETCHE, M. e RODDEN, J. (2004). Política distributiva na federação: estratégias eleitorais, barganhas legislativas e coalizões de governo. DADOS - Revista de Ciências Sociais. Rio de Janeiro, v. 47, n. 3, pp. 549-576.

BRASIL - Ministério do Desenvolvimento Social e Combate à Fome (2006). Análise do custo de geração de postos de trabalho na economia urbana para o segmento dos catadores de materiais recicláveis. Brasília.

Fundação Nacional de Saúde - Funasa (2010a). Programas municipais de coleta seletiva de lixo como fator de sustentabilidade dos sistemas públicos de saneamento ambiental na Região Metropolitana de São Paulo. Brasília, Fundação Nacional de Saúde.

(2010b). Lei n. 12.305, de 2 de agosto de 2010. Institui a Política Nacional de Resíduos Sólidos; altera a lei n. 9.605, de 12 de fevereiro de 1998; e dá outras providências. Diário Oficial da União. Brasília, DF, 3 ago. Seção 1, p. 3.

Tribunal de Contas da União (2013). Convênios e outros repasses. 4 ed. Brasília, SecretariaGeral de Controle Externo.

Ministério das Cidades. Secretaria Nacional de Saneamento Ambiental (2014). PLANSAB Plano Nacional de Saneamento Básico: mais saúde com qualidade de vida e cidadania. Brasília.

Ministério das Cidades. Secretaria Nacional de Saneamento Ambiental - SNSA (2017). Sistema nacional de informações sobre saneamento: diagnóstico do manejo de resíduos sólidos urbanos - 2015. Brasília, MCidades. SNSA.

CETESB - Companhia Ambiental do Estado de São Paulo (2006). Inventário estadual de resíduos sólidos domiciliares 2005. São Paulo, Cetesb. Disponível em: <http://www.cetesb.sp.gov.br/solo/ publicações-e-relatórios/1-publicaçõs-/-relatórios>. Acesso em: 12 mar 2013.

CHEN, X.; GENG, Y. e FUJITA, T. (2010). An overview of municipal solid waste management in China. Waste Management, n. 30, pp. 716-724.

CHERFEM, C. O. (2015). A coleta seletiva e as contradições para a inclusão de catadoras e catadores de materiais recicláveis: construção de indicadores sociais. Mercado de trabalho: conjuntura e análise. Brasília, Ipea, pp. 89-98.

FARAH, M. F. S. (2006). "Inovação e governo local no Brasil contemporâneo". In: JACOBI, P. e PINHO, J. A. (orgs.). Inovação no campo da gestão pública local: novos desafios, novos patamares. Rio de Janeiro, FGV.

FURTADO, C. (1999). O longo amanhecer: reflexões sobre a formação do Brasil. Rio de Janeiro, Paz e Terra. 
GARCIA, R. C. (2015). “Despesas correntes da União: visões, omissões e opções”. In: CARDOSO Jr., J. C. e CUNHA, A. S. (orgs.). Planejamento e avaliação de políticas públicas. Brasília, IPEA, pp. 147-182.

IBGE - Instituto Brasileiro de Geografia e Estatística (2014). Produto Interno Bruto dos Municípios 2012. Rio de Janeiro.

KLEIN, F. B. (2017). Por dentro da caixa-preta das políticas municipais de resíduos sólidos urbanos: os arranjos institucionais e a implementação da Política Nacional de Resíduos Sólidos. Dissertação de Mestrado. São Paulo, Universidade de São Paulo.

MIRANDA SOARES, M. e GUIMARÃES de MELO, B. (2016). Condicionantes políticos e técnicos das transferências voluntárias da União aos municípios brasileiros. Revista de Administração Pública RAP, v. 50, n. 4, pp. 539-561.

MOGI DAS CRUZES (Município) (2013). Plano Municipal Integrado de Gestão de Resíduos Sólidos (diagnóstico - produto 1). Mogi das Cruzes. Disponível em: <http://www.mogidascruzes.sp.gov. br/>. Acesso em: 14 jun 2015.

OLIVIERI, C. (2010). "Monitoramento das políticas públicas e controle da burocracia: o sistema de controle interno do Executivo federal brasileiro". In: LOUREIRO, M. R.; ABRUCIO, F. L. e PACHECO, R. S. (orgs.) Burocracia e política no Brasil: desafios para a ordem democrática no século XXI. Rio de Janeiro, FGV, pp. 149-180.

O’TOOLE, L. J. Jr. (2003). “Inteorganizacional relations in implementation”. In: PETERS, B. G. e PIERRE, J. (eds.). Handbook of public administration. Londres, Sage Publications, pp. 234-244.

PARES, A. e VALLE, B. (2006). "A retomada do planejamento governamental no Brasil e seus desafios". In: GIACOMONI, J. e PAGNUSSAT, J. L. (orgs.). Planejamento e orçamento governamental: coletânea. Brasília, Enap.

PASTERNAK, S. e BÓGUS, L. M. M. (2011). Urbanização, meio ambiente e saúde em São Paulo. InterfacEHS, v. 6, n. 2, pp. 52-72.

POLLITT, C. e BOUCKAERT, G. (2011). Public management reform: a comparative analysis. Oxford, Oxford University.

PRADO, S. R. R.; QUADROS, W. e CAVALCANTI, C. E. (2003). Partilha de recursos na federação brasileira. São Paulo, Fapesp e Fundap/Brasília, Ipea.

RAMOS, M. P. e SCHABBACH, L. M. (2012). O estado da arte da avaliação de políticas públicas: conceituação e exemplos de avaliação no Brasil. Revista de Administração Pública [on-line], v. 46, n. 5.

REZENDE, F. (1995). “O financiamento das políticas públicas: problemas atuais”. In: AFFONSO, R. de B. A. e SILVA, P. L. B. A federação em perspectiva: ensaios selecionados. São Paulo, Fundap, pp. 241-259.

SANTOS, M. C. L. e GONÇALVES-DIAS, S. L. F. (2012). “Gestão de resíduos na cidade de São Paulo: um problema, múltiplas soluções". In: PADOVANO, B. R.; NAMUR, M. e BERTACCHINI SALA, P. (orgs.) São Paulo: em busca da sustentabilidade. São Paulo, Edusp e Pini, v. 1, pp. 146-159.

SILVA, C. B. e LIPORONE, F. (2011). Deposição irregular de resíduos sólidos domésticos em Uberlândia: algumas considerações. OBSERVATORIUM: Revista Eletrônica de Geografia, v. 2, n. 6, pp. 22-35.

SILVA, P. L. B. e COSTA, V. L. C. (1995). “Descentralização e crise da federação”. In: AFFONSO, R. B. A. e SILVA, P. L. B. A federação em perspectiva: ensaios selecionados. São Paulo, Fundap, pp. 261-283.

SILVA, L. S. e TRAVASSOS, L. (2008). Problemas ambientais urbanos: desafios para a elaboração de políticas públicas integradas. Cadernos Metrópole. São Paulo, v. 10, n. 19, pp. 27-47. 
TEIXEIRA, E. C. (2009). "Introdução à macroeconomia”. In: VIAN, C. E. F. (org.). Introdução à economia. Campinas, Alínea, pp. 173-186.

VELOSO, J. F. A. et al. (orgs). (2011). Gestão municipal no Brasil: um retrato das prefeituras. Brasília, Ipea.

ZANTA, V. M. (2009). “A sustentabilidade dos serviços públicos de resíduos sólidos: novas oportunidades e velhos desafios". In: CORDEIRO, B. de S. (coord.) Livro II: Conceitos, características e interfaces dos serviços públicos de saneamento básico. Brasília, Ministério das Cidades, pp. 295-304.

Texto recebido em 4/ago/2018

Texto aprovado em 30/jan/2019 